\title{
Autophagy patterns and prognosis in uveal melanomas
}

\author{
Alexandra N Giatromanolaki ${ }^{1}$, Georgios St Charitoudis ${ }^{2}$, Nikolaos E Bechrakis ${ }^{3}$, \\ Vassilios P Kozobolis ${ }^{4}$, Michael I Koukourakis ${ }^{5}$, Michael H Foerster ${ }^{2}$ and \\ Efthimios L Sivridis ${ }^{1}$ \\ ${ }^{1}$ Department of Pathology, Democritus University of Thrace Medical School, Alexandroupolis, Greece; \\ ${ }^{2}$ Department of Ophthalmology, Charité Medical University, Campus Benjamin Franklin, Berlin, Germany; \\ ${ }^{3}$ Department of Ophthalmology, University of Innsbruck Medical School, Innsbruck, Austria; ${ }^{4}$ Department of \\ Ophthalmology, Democritus University of Thrace Medical School, Alexandroupolis, Greece and ${ }^{5}$ Department \\ of Radiotherapy/Oncology, Democritus University of Thrace Medical School, Alexandroupolis, Greece
}

\begin{abstract}
Autophagy is a self-degradation mechanism by which cells recycle their own cytoplasmic constituents. It has been claimed that, under certain conditions, such a process may be associated with tumor progression. In this study, the autophagic activity was investigated in a series of 99 uveal melanomas after immunohistochemical staining for the autophagy-associated proteins MAP1LC3A and BECN1, most commonly known as LC3A and Beclin 1, respectively. These were assessed in parallel with the hypoxia-inducible factor $1 \alpha(H I F 1 A)$ and its downstream protein lactate dehydrogenase 5 (composed by five LDHA subunits). Increased autophagic reactivity, detected by MAP1LC3A or BECN1, was associated with intense pigmentation and tumor hypoxia. Uveal melanomas with extensive overexpression of BECN1 or those with underexpression of this protein were associated with the worst prognosis, but the former manifested metastases much earlier than the latter; only $58 \%$ of patients with extensive BECN1 overexpression were alive at 4 years, compared with $80 \%$ of patients with underexpressed patterns. It is concluded that autophagy is commonly upregulated in uveal melanomas, and may be associated with hypoxia and intense pigmentation. There is a strong association between extensive $B E C N 1$ overexpression and early metastases/poor prognosis, and between underexpression of this protein and late metastases/better prognosis.

Modern Pathology (2011) 24, 1036-1045; doi:10.1038/modpathol.2011.63; published online 15 April 2011
\end{abstract}

Keywords: autophagy; BECN1; HIF1A; hypoxia; LDHA; MAP1LC3A; uveal melanoma

Autophagy is a self-degradation mechanism by which cells recycle their long-lived proteins and defective organelles under conditions of microenvironmental stress, such as oxygen depletion and nutrient deprivation. ${ }^{1}$ By disposing excess or defective cytoplasmic components into the lysosomes, cells renew themselves acquiring, at the same time, energy through metabolic consumption of the digested material. Although autophagy is a major cell survival pathway, its excessive activation leads to massive degradation of cellular components, shifting the balance to self-destruction and autop-

Correspondence: Dr A Giatromanolaki, MD, Department of Pathology, Democritus University of Thrace Medical School, University General Hospital of Alexandroupolis, PO Box 128, Alexandroupolis 68100, Greece.

E-mail: agiatrom@med.duth.gr or targ@her.forthnet.gr

Received 2 October 2010; revised 11 January 2011; accepted 11 January 2011; published online 15 April 2011 hagic cell death. Several studies suggest that autophagy is intensified in neoplastic cells, but its role in growth and progression of human malignancies remains poorly understood and even more complex is its significance in the response of neoplastic cells to various cytotoxic agents and radiation. ${ }^{2}$

Autophagy is characterized by the formation of double membrane vacuoles containing cytoplasmic constituents, the autophagosomes; these are fused with lysosomes to form the autolysosomes and which subsequently degrade and recycle the sequestered material. An essential component of the autophagic vacuoles is the microtubule-associated protein 1 light chain 3 , that is MAP1LC3A (LC3A)-a homolog of yeast autophagy-related (Atg) protein 8 . $M A P 1 L C 3 A$ exists in two forms, the MAP1LC3A-I (cytosolic) and the MAP1LC3A-II (membrane bound)..$^{3-5}$ MAP1LC3A-I (18 kDa) is derived from a proLC3 $(30 \mathrm{kDa})$ protein after cleavage by Atg4. 
Following activation by Atg7 and Atg3, MAP1LC3A-I is converted into the membrane-bound form MAP1LC3A-II (16 kDa). ${ }^{5}$ The latter binds tightly to preautophagosomal, autophagosomal and autolysosomal membranes forming a suitable marker of autophagic activity. ${ }^{3-5}$

$B E C N 1$ (Beclin 1) is the mammalian ortholog of yeast Atg6 gene, which is essential for autophagosome formation. ${ }^{6,7}$ The human Beclin 1 gene resides on chromosome $17 \mathrm{q} 21$ and is monoallelicaly deleted in many human breast, ovarian and prostatic cancer cell lines. ${ }^{6-9}$ Furthermore, Beclin $1^{+/-}$mutant mice suffer from high incidence of spontaneous tumors, suggesting that BECN1 has a tumor suppressor function $^{6,7,9-11}$ with a regulatory role in autophagy. ${ }^{11}$

Hypoxia is a prevailing feature in malignant tissues mainly because of an insufficient, and often immature, vascular network that prevents adequate blood and oxygen perfusion. ${ }^{12,13}$ Experimental studies suggest that hypoxia is a potent stress stimulus triggering autophagy in normal and malignant cells. ${ }^{14}$ The hypoxia-inducible factor $H I F 1 A$, a key transcription factor regulating the expression of a variety of genes involved in angiogenesis and anaerobic metabolism, ${ }^{15}$ is also involved in the regulation of autophagy in neoplastic cells under hypoxic conditions. ${ }^{16-18}$

In the present study, we investigated the autophagic process and its relationship to prognosis in a series of 99 uveal melanomas after immunohistochemical staining for the Atg proteins MAP1LC3A and BECN1. The possible relationship between autophagy and intratumoral hypoxia, assessed by the expression of HIF1A and its downstream protein lactate dehydrogenase $5,{ }^{15}$ was also sought. Note that LDH5 is composed of five $L D H A$ subunits.

\section{Materials and methods}

\section{Tissue Specimens}

A total of 99 uveal melanomas treated with enucleation at the Department of Ophthalmology, Charité Medical University, Campus Benjamin Franklin, Berlin were included in this study. None of the patients had been treated with radiotherapy before or after the operation. The median follow-up was 79 months (range 6-154 months). Informed consent was obtained from the patients. The study was also approved by the Research Committee of the Democritus University of Thrace/University General Hospital of Alexandroupolis, where it was conducted.

The specimens had been fixed in 10\% formalin and processed routinely to paraffin wax. Following histopathological examination, the melanoma cells were assigned to cell types (spindle cell, epithelioid, and mixed-cell type with spindle or epithelioid cell predominance) and assessed for localization, pigmentation, and necrosis, as indicated in Tables 1
Table 1 Clinical characteristics and histopathological features in patients with uveal melanomas

\begin{tabular}{|c|c|}
\hline & No. cases \\
\hline Number of patients & 99 \\
\hline \multicolumn{2}{|l|}{ Age (years) } \\
\hline Median (range) & $62(26-89)$ \\
\hline \multicolumn{2}{|l|}{ Sex } \\
\hline Female/male & $53 / 46$ \\
\hline \multicolumn{2}{|l|}{ Melanoma cell type } \\
\hline Spindle cells & 27 \\
\hline Mixed, with spindle cells prevailing & 54 \\
\hline Mixed, with epithelioid cells prevailing & 12 \\
\hline Epithelioid cells & 6 \\
\hline \multicolumn{2}{|l|}{ Localization } \\
\hline Ciliary body & 2 \\
\hline Ciliary body and choroid & 31 \\
\hline Choroid anteriorly to equator & 20 \\
\hline Posterior pole & 46 \\
\hline \multicolumn{2}{|l|}{ Pigmentation } \\
\hline Low (absent and minimal) & 36 \\
\hline High & 63 \\
\hline \multicolumn{2}{|l|}{ Necrosis } \\
\hline Limited (absent and minimal) & 76 \\
\hline Extensive & 23 \\
\hline \multicolumn{2}{|l|}{ Tumor size } \\
\hline \multicolumn{2}{|l|}{ Diameter at the base } \\
\hline$\leq 15 \mathrm{~mm}$ & 56 \\
\hline$>15 \mathrm{~mm}$ & 43 \\
\hline \multicolumn{2}{|l|}{ Height } \\
\hline$\leq 8 \mathrm{~mm}$ & 45 \\
\hline$>8 \mathrm{~mm}$ & 44 \\
\hline
\end{tabular}

and 2. Tumor thickness was assessed by ultrasonography.

The Primary Antibodies and the Immunohistochemical Techniques

Autophagy was detected by a standard immunohistochemical technique using two different primary antibodies: the purified rabbit polyclonal antibody MAP1LC3A (AP1805a; Abgent, San Diego, CA, USA) at $1: 20$ dilution; ${ }^{19-21}$ and the rabbit monoclonal antibody EPR1733Y to BECN1 (ab51031; Abcam, Cambridge, UK), used at a dilution 1:50. ${ }^{22}$

The detection of hypoxia-related proteins HIF1A and $L D H A$ (LDH5 isoenzyme) was achieved after employing a further two markers: the ESEE122 monoclonal antibody (Oxford University, UK) at dilution 1:20 and overnight incubation, for identification of the HIF1A protein $;^{23}$ and the polyclonal antibody ab9002 (Abcam) at dilution $25 \mu \mathrm{g} / \mathrm{ml}$ and $75 \mathrm{~min}$ incubation, for revealing LDHA (LDH5 isoenzyme). ${ }^{24,25}$ 
Table 2 Association of MAP1LC3A expression with pathological parameters in 99 uveal melanomas

\begin{tabular}{|c|c|c|c|c|c|c|}
\hline & \multicolumn{3}{|c|}{ MAP1LC3A cytoplasmic } & \multicolumn{3}{|c|}{ MAP1LC3A perinuclear } \\
\hline & Low & High & $\mathrm{P}$-value & Low & High & $\mathrm{P}$-value \\
\hline \multicolumn{7}{|l|}{ Cell type } \\
\hline Spindle cells & 17 & 10 & & 20 & 7 & \\
\hline Mixed/spindle cells prevailing & 29 & 25 & 0.46 & 35 & 19 & 0.42 \\
\hline Mixed/epitheliod cells prevailing & 8 & 4 & & 7 & 5 & \\
\hline Epithelioid cells & 5 & 1 & & 6 & 0 & \\
\hline \multicolumn{7}{|l|}{ Location } \\
\hline Ciliary body & 2 & 0 & & 2 & 0 & \\
\hline Ciliary body and choroid & 16 & 15 & 0.25 & 15 & 16 & $0.005^{\mathrm{a}}$ \\
\hline Choroid anteriorly to equator & 10 & 10 & & 13 & 7 & \\
\hline Posterior pole & 31 & 15 & & 38 & 8 & \\
\hline \multicolumn{7}{|l|}{ Pigmentation } \\
\hline Low (absent and minimal) & 26 & 10 & 0.05 & 33 & 3 & 0.0002 \\
\hline High & 33 & 30 & & 35 & 28 & \\
\hline \multicolumn{7}{|l|}{ Tumor necrosis } \\
\hline Limited (absent and minimal) & 47 & 29 & 0.40 & 54 & 22 & 0.35 \\
\hline Extensive & 12 & 11 & & 14 & 9 & \\
\hline \multicolumn{7}{|l|}{ Tumor size } \\
\hline \multicolumn{7}{|l|}{ Diameter at the base } \\
\hline$\leq 15 \mathrm{~mm}$ & 37 & 19 & 0.13 & 41 & 15 & 0.26 \\
\hline$>15 \mathrm{~mm}$ & 22 & 21 & & 27 & 16 & \\
\hline \multicolumn{7}{|l|}{ Height } \\
\hline$\leq 8 \mathrm{~mm}$ & 30 & 15 & 0.19 & 29 & 16 & 0.40 \\
\hline$>8 \mathrm{~mm}$ & 29 & 25 & & 39 & 15 & \\
\hline
\end{tabular}

${ }^{\mathrm{a}}$ Posterior pole vs other.

Tissue sections from uveal melanomas were cut at $3 \mu \mathrm{m}$ and stained immunohistochemically as previously described. ${ }^{19-25}$

\section{Evaluation of Autophagic Activity and Hypoxia}

The patterns of MAP1LC3A expression in uveal melanomas were diffuse cytoplasmic and cytoplasmic/juxta-nuclear (Figure $1 \mathrm{a}$ and b). These were evaluated as follows. The proportion of tumor cells showing a diffuse cytoplasmic reactivity per section was determined at $\times 200$ magnification. Using the $50 \%$ as a cutoff point, cases were divided into groups of low $(\leq 50 \%)$ and high $(>50 \%)$ cytoplasmic $M A P 1 L C 3 A$ reactivity. The proportion of tumor cells expressing the perinuclear MAP1LC3A pattern was assessed in a similar manner. These tumors were meant to be separated into groups of low, intermediate, and high reactivity using the 33rd and 67th percentiles. However, as the 67 th percentile was $0 \%$, two groups of perinuclear reactivity were eventually formed, the low and the high (see Results).

The reactivity of $B E C N 1$ in uveal melanomas was in all cases diffuse cytoplasmic and was evaluated, on the basis of the extent and intensity of staining, at $\times 200$ magnification, as previously indicated: ${ }^{22}$

1. Low level: when cytoplasmic reactivity expressed strongly in $<10 \%$ of tumor cells, and/or weakly in $>90 \%$ of tumor cells (Figure 1c);
2. Overexpression: when $>10 \%$ of tumor cells showed a strong cytoplasmic reactivity, and no $>50 \%$ were negative; overexpression was considered as being (2a) extensive, when $>50 \%$ of neoplastic cells expressed strong BECN1 reactivity or (2b) limited, when $10-50 \%$ of tumor cells showed a similar reaction (Figure 1d);

3. Underexpression: if $>50 \%$ of tumor cells in a section were negative.

HIF1A and LDHA (LDH5 isoenzyme) reactivity was mixed cytoplasmic and nuclear. The percentage of melanoma cells with nuclear and/or strong cytoplasmic HIF1A expression was assessed separately in all optical fields at $\times 200$ magnification and the mean value of all fields was used to score each case. Melanomas with nuclear $H I F 1 A$ expression in $>10 \%$ of tumor cells and/or strong cytoplasmic expression in $>50 \%$ of tumor cells were considered as being of high reactivity. ${ }^{26} \mathrm{LDHA}$ (LDH5 isoenzyme) was evaluated in a similar way. The assessment was performed blindly by two independent observers (AG and ES).

\section{Western Blotting}

In order to validate the specificity of $M A P 1 L C 3 A$ antibody, a western blot analysis of mouse liver supernatant and pellet extracts was performed using the AP1805a antibody. 

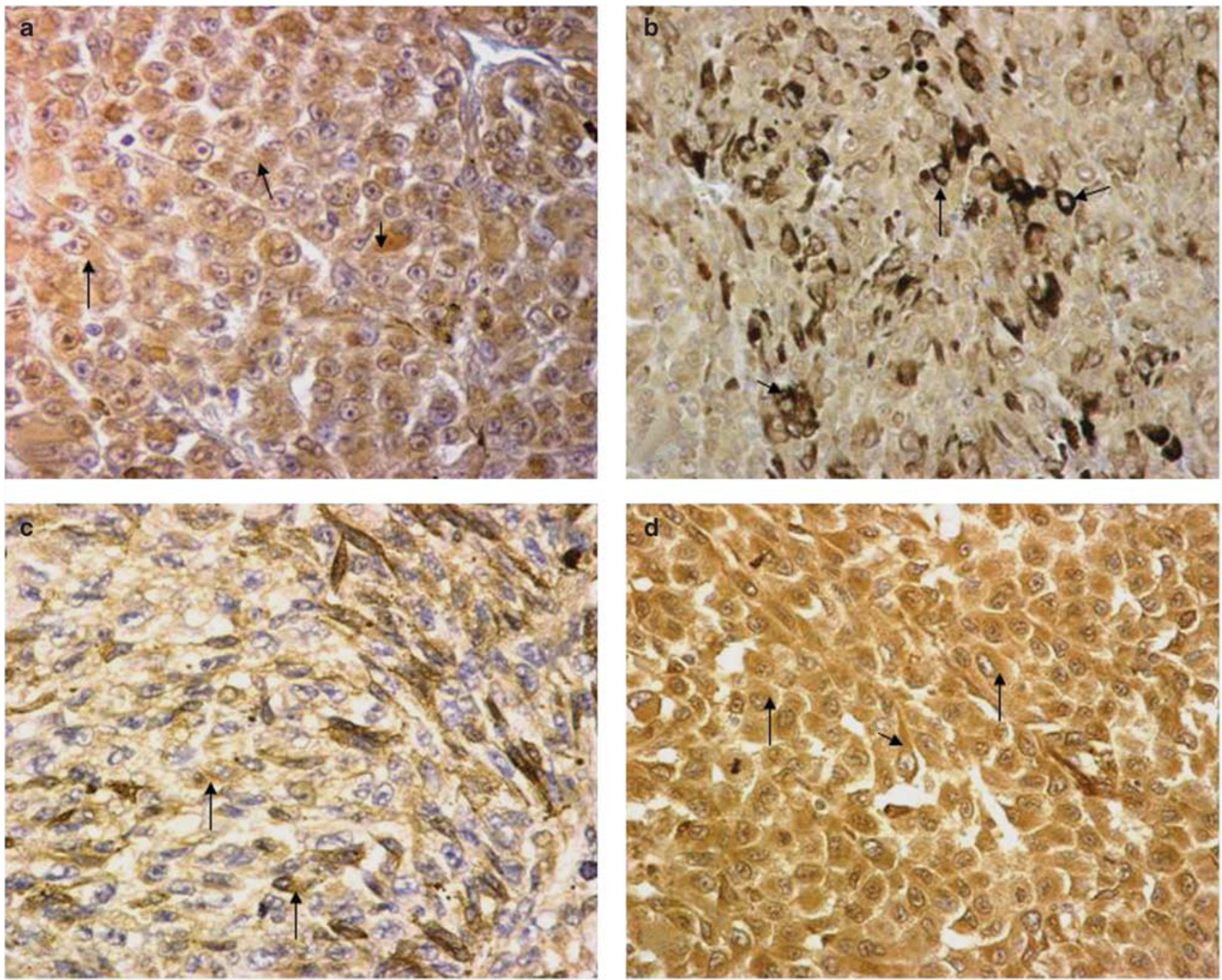

Figure 1 (a) Diffuse cytoplasmic pattern of MAP1LC3A in a uveal melanoma. (b) Cytoplasmic/perinuclear pattern of $M A P 1 L C 3 A$ in a uveal melanoma. (c) Weak cytoplasmic reactivity of BECN1 in a uveal melanoma. (d) Strong cytoplasmic reactivity of BECN1 in a uveal melanoma.

\section{Statistical Analysis}

Statistical analysis was performed using the GraphPad Prism 5.0 package (GraphPad, San Diego, CA, USA; http://www.graphpad.com). The $\chi^{2}$, the Fisher's exact $t$-test, or the unpaired two-tailed $t$-test was used for testing relationships between categorical variables. Linear regression analysis was used to compare groups of continues variables. A $P$-value $\leq 0.05$ was considered significant.

\section{Results}

Table 1 shows the patient characteristics and the histopathological features of all uveal melanomas in the series. The diameter of the tumors, assessed by ultrasonography, ranged from 4 to $23 \mathrm{~mm}$ (median $15 \mathrm{~mm}$ ) at the base of the lesions, and was from 1 to $22 \mathrm{~mm}$ (median $9 \mathrm{~mm}$ ) height.

\section{MAP1LC3A Antibody Validation}

Validation of MAP1LC3A antibody's specificity (AP1805a; Abgent), performed by western blot analysis of mouse liver extracts, gave two bands corresponding to the MAP1LC3A-I and II proteins (Figure 2).

\section{MAP1LC3A and BECN1 Expression Patterns}

After immunohistochemical staining for $M A P 1 L$ $C 3 A$, two distinct patterns of cytoplasmic expression were consistently recognized in uveal melanomas: the diffuse cytoplasmic, and the cytoplasmic/juxta-nuclear occurring in a crescentic or ring-like (perinuclear) manner. A third pattern, the so-called 'stone-like structures', reported earlier in a number of epithelial tumors by our group, was not detected in uveal melanomas. ${ }^{19,27}$ 


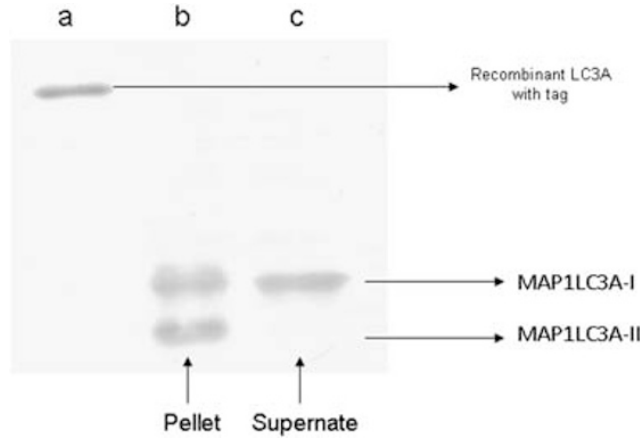

Figure 2 Western blotting showing (a) the band of recombinant $M A P 1 L C 3 A$ protein with tag, (b) the two bands of $M A P 1 L C 3 A$, the MAP1LC3A-I (soluble), and the MAP1LC3A-II (membrane bound) form, in the pellet from mouse liver, and (c) MAP1LC3A-II, but not $M A P 1 L C 3 A-I$, in the supernate of the tissue.

The diffuse cytoplasmic MAP1LC3A pattern varied considerably between cases, ranging from 0 to $100 \%$ of melanoma cells (median $40 \%$ ). Using the 50 th $(50 \%)$ percentile, the cases were divided into groups of low $(0-50 \%, 59$ cases), and high (51-100\%, 40 cases) cytoplasmic reactivity.

The perinuclear MAP1LC3A pattern also varied between cases, ranging from 0 to $90 \%$ of tumor cells (median $0 \%$ ). The $33 \mathrm{rd}$ and 67 th percentiles were $0 \%$, so cases were grouped in two categories of low $(0 \%, 68$ cases) and high $(10-90 \%, 31$ cases $)$ perinuclear reactivity.

$B E C N 1$ was diffusely expressed in the cytoplasm of melanoma cells. Overexpression was evident in $48 / 99$ cases (48.4\%), of which $22 / 99(22.2 \%)$ were extensive ( $>50 \%$ of cells), and $26 / 99(26.2 \%$ ) were limited. Underexpression was noted in 29/99 $(29.3 \%)$ cases, while a basal level of BECN1 activity was seen in 22/99 (22.2\%) cases.

Both high cytoplasmic and perinuclear $M A P 1 L-$ $C 3 A$ expression were related with extensive beclin 1 overexpression $(P=0.02$ and $P=0.03$, respectively) (Table 4).

\section{Intra- and Inter-observer Variability}

The immunohistochemical expression patterns for MAP1LC3A (cytoplasmic and perinuclear) and $B E C N 1$ (cytoplasmic) were examined for intra- and inter-observer variability. Two experienced pathologists assessed the slides separately and repeated the assessment 30 days later. The second assessment was highly correlated with the first for all observers $(r>0.97, \quad P<0.0001$ for all three parameters). Similarly, the two investigator's scoring correlated to each other for all three variables $(r>0.92$, $P<0.0001)$. The final decision was taken on the conference microscope.

\section{MAP1LC3A and BECN1 in Relation to Pathological Features}

Both high cytoplasmic and perinuclear MAP1LC3A patterns were linked with intense pigmentation of uveal melanomas $(P=0.01$ and $P=0.0002$, respectively).

Uveal melanomas composed exclusively of spindle cells were declining to express BECN1 $(P=0.005)$ (Table 3). Overexpression of BECN1, whether limited or extensive, was linked with intense pigmentation $(P=0.01)$.

There was a significant association between high cytoplasmic MAP1LC3A expression and extensive overexpression of $B E C N 1 \quad(P=0.03)$, and between high perinuclear MAP1LC3A expression and the overall BECN1 overexpression $(P=0.03)$ (Table 4$)$.

\section{MAP1LC3A and Hypoxia-Related Proteins}

Linear regression analysis showed that perinuclear, but not the cytoplasmic, MAP1LC3A pattern expression was directly linked with the hypoxia-related proteins HIF1A and LDHA (LDH5 isoenzyme) (Table 5). The same applied to BECN1. No association was noted between cytoplasmic MAP1LC3A pattern and the hypoxia-linked proteins.

In group analysis, a high perinuclear MAP1LC3A expression was associated with a high LDHA (LDH5 isoenzyme) expression, both cytoplasmic $(P<0.0001)$ and nuclear $(P<0.0001)$. Similarly, an increased perinuclear MAP1LC3A expression was connected with HIF1A expression, whether cytoplasmic or nuclear, but the difference was not significant $(P=0.15$ and 0.12 , respectively) (data not shown).

\section{Survival Analysis}

Table 6 shows the univariate and multivariate analysis of metastatic and death events. The presence of an epithelioid component in uveal melanomas was linked with a poor metastasis-free and overall survival ( $P=0.02$ and 0.02 , respectively). At univariate analysis, an extensive overexpression of BECN1 as well as an underexpression of this protein were linked with poor metastasis-free interval and disease-specific overall survival $(P=0.01)$.

Figure 3 shows that patients being almost at the two extremes of BECN1 expression, that is, patients with extensive overexpression of BECN1 and those with underexpression of this protein had the worse prognosis. Nevertheless, the former manifested metastases much earlier than the latter. In fact, in the presence of extensive overexpression of BECN1, only $58 \%$ of the patients were alive at 4 years. By contrast, underexpression patterns correlated with delayed appearance of metastases and death events, with over $80 \%$ of patients being alive at 4 years $(P=0.02$ for metastasis and $P=0.05$ for death events).

In multivariate analysis, the patterns of BECN1 expression and the presence of an epithelioid component were the only prognostic variables that maintained an independent significance (Table 6). 
Table 3 Association of BECN1 expression with pathological parameters in 99 uveal melanomas

\begin{tabular}{|c|c|c|c|c|c|}
\hline & \multirow[t]{2}{*}{ Underexpression } & \multirow[t]{2}{*}{ Low level } & \multicolumn{2}{|c|}{ Overexpression } & \multirow[t]{2}{*}{$\mathrm{P}$-value } \\
\hline & & & Limited & Extensive & \\
\hline \multicolumn{6}{|l|}{ Cell type } \\
\hline Spindle cells & 14 & 3 & 4 & 6 & \\
\hline Mixed/spindle cells prevailing & 12 & 8 & 13 & 21 & $0.005^{\mathrm{a}}$ \\
\hline Mixed/epitheliod cells prevailing & 1 & 4 & 4 & 3 & \\
\hline Epithelioid cells & 2 & 0 & 1 & 3 & \\
\hline \multicolumn{6}{|l|}{ Location } \\
\hline Ciliary body & 0 & 0 & 1 & 1 & \\
\hline Ciliary body and choroid & 7 & 4 & 10 & 10 & 0.20 \\
\hline Choroid anteriorly to equator & 7 & 1 & 2 & 10 & \\
\hline Posterior pole & 15 & 10 & 9 & 12 & \\
\hline \multicolumn{6}{|l|}{ Pigmentation } \\
\hline Low (absent and minimal) & 16 & 6 & 7 & 7 & $0.01^{\mathrm{b}}$ \\
\hline High & 13 & 9 & 15 & 26 & \\
\hline \multicolumn{6}{|l|}{ Tumor necrosis } \\
\hline Limited (absent and minimal) & 23 & 12 & 16 & 25 & 0.93 \\
\hline Extensive & 6 & 3 & 6 & 8 & \\
\hline \multicolumn{6}{|l|}{ Tumor size } \\
\hline \multicolumn{6}{|l|}{ Diameter at the base } \\
\hline$\leq 15 \mathrm{~mm}$ & 19 & 9 & 8 & 19 & 0.20 \\
\hline$>15 \mathrm{~mm}$ & 10 & 6 & 14 & 14 & \\
\hline \multicolumn{6}{|l|}{ Height } \\
\hline$\leq 8 \mathrm{~mm}$ & 15 & 8 & 7 & 15 & 0.47 \\
\hline$>8 \mathrm{~mm}$ & 14 & 7 & 15 & 18 & \\
\hline
\end{tabular}

${ }^{\mathrm{a}}$ Pure spindle cell vs presence of epithelioid component/underexpression Beclin 1 vs all other.

${ }^{\mathrm{b}}$ Underexpression/low level vs limited/extensive overexpression.

Table 4 Association between MAP1LC3A and BECN1 expression

\begin{tabular}{|c|c|c|c|c|c|c|}
\hline & \multicolumn{3}{|c|}{ MAP1LC3A cytoplasmic } & \multicolumn{3}{|c|}{ MAP1LC3A perinuclear } \\
\hline & Low & High & $\mathrm{P}$-value & Low & High & $\mathrm{P}$-value \\
\hline \multicolumn{7}{|l|}{ MAP1LC3A perinuclear } \\
\hline High & 18 & 13 & & - & - & - \\
\hline Low & 41 & 27 & 0.82 & - & - & - \\
\hline \multicolumn{7}{|l|}{ BECN1 } \\
\hline Overexpression, extensive & 15 & 18 & & 21 & 12 & \\
\hline Overexpression, limited & 15 & 7 & & 12 & 10 & \\
\hline Low level & 9 & 6 & & 14 & 1 & \\
\hline Underexpression & 20 & 9 & $0.04^{\mathrm{a}}$ & 21 & 8 & $0.03^{\mathrm{a}}$ \\
\hline
\end{tabular}

${ }^{\mathrm{a}}$ Extensive overexpression vs all other.

\section{Discussion}

Hypoxia is a major microenvironmental condition in solid tumors that defines tumor aggressiveness either by selecting resistant sub-populations of cancer cells or by triggering specific molecular pathways that facilitate tumor growth, invasiveness, and metastasis. ${ }^{28,29}$ Hypoxic cells have been detected in human melanoma xenografts by pimonidazole immunohistochemistry ${ }^{30}$ and, indeed, were shown to promote metastatic spread. ${ }^{31,32}$ HIF1A, in particular, is largely expressed in human neoplasia, including melanomas, and is linked with metasta$\operatorname{sis}^{33,34}$ and melanocyte transformation, in conjunction with the Akt gene. ${ }^{35}$

Furthermore, HIF1A is actively involved in triggering autophagy, a major intracellular pathway promoting the survival of tumor cells under oxygen and nutrient deprivation. ${ }^{16-18}$ This autophagic process has been documented in human melanomas as early as 1982 by Horikoshi et $a l,{ }^{36}$ and melanoma cells are known to induce autophagic activity with 
Table 5 Linear regression analysis of the percentage of melanoma cells expressing strongly BECN1 and cytoplasmic or perinuclear $M A P 1 L C 3 A$ patterns according to cytoplasmic or nuclear expression of HIF1A and LDHA (LDH5 isoenzyme)

\begin{tabular}{|c|c|c|c|c|c|c|}
\hline & \multicolumn{2}{|c|}{ MAP1LC3A cytoplasmic } & \multicolumn{2}{|c|}{ MAP1LC3A perinuclear } & \multicolumn{2}{|c|}{$B E C N 1$} \\
\hline & $\mathrm{P}$-value & r-value & P-value & r-value & $\mathrm{P}$-value & r-value \\
\hline \multicolumn{7}{|l|}{ HIF1A } \\
\hline Cytoplasmic & 0.53 & 0.07 & 0.02 & 0.24 & 0.008 & 0.30 \\
\hline Nuclear & 0.55 & 0.06 & 0.0002 & 0.41 & 0.14 & 0.17 \\
\hline \multicolumn{7}{|c|}{ LDHA (LDH5 isoenzyme) } \\
\hline Cytoplasmic & 0.34 & 0.10 & $<0.0001$ & 0.68 & $<0.0001$ & 0.55 \\
\hline Nuclear & 0.72 & 0.03 & $<0.0001$ & 0.61 & 0.001 & 0.36 \\
\hline
\end{tabular}

Table 6 Univariate and multivariate analysis in metastatic and death events in 99 uveal melanomas

\begin{tabular}{|c|c|c|c|c|}
\hline \multirow[t]{2}{*}{ Variable } & \multicolumn{2}{|c|}{ Univariate } & \multicolumn{2}{|c|}{ Multivariate } \\
\hline & H-ratio & P-value & t-ratio & $\mathrm{P}$-value \\
\hline \multicolumn{5}{|l|}{ Metastatic events } \\
\hline LC3 cytoplasmic ${ }^{a}$ & 0.85 & 0.66 & 0.45 & 0.64 \\
\hline LC3 perinuclearb & 0.61 & 0.18 & 1.07 & 0.28 \\
\hline$B E C N 1^{\mathrm{c}}$ & 3.60 & $<0.0001$ & 4.62 & $<0.0001$ \\
\hline Histology $^{\mathrm{d}}$ & 0.45 & 0.02 & 2.96 & 0.004 \\
\hline Diameter $^{\mathrm{e}}$ & 1.14 & 0.67 & 0.35 & 0.72 \\
\hline Height $^{\mathrm{f}}$ & 1.35 & 0.34 & 0.27 & 0.78 \\
\hline Pigmentationg & 0.67 & 0.23 & 0.29 & 0.76 \\
\hline Necrosis $^{\mathrm{h}}$ & 0.67 & 0.33 & 0.54 & 0.58 \\
\hline \multicolumn{5}{|l|}{ Death events } \\
\hline LC3 cytoplasmic ${ }^{a}$ & 0.96 & 0.92 & 0.48 & 0.62 \\
\hline LC3 perinuclear ${ }^{\mathrm{b}}$ & 0.60 & 0.18 & 0.90 & 0.36 \\
\hline$B E C N 1^{\mathrm{c}}$ & 3.83 & 0.0002 & 4.71 & $<0.0001$ \\
\hline Histology ${ }^{\mathrm{d}}$ & 0.44 & 0.02 & 3.18 & 0.002 \\
\hline Diameter $^{\mathrm{e}}$ & 1.04 & 0.90 & 1.17 & 0.24 \\
\hline Height $^{f}$ & 1.45 & 0.26 & 0.93 & 0.35 \\
\hline Pigmentation ${ }^{\mathrm{g}}$ & 0.70 & 0.29 & 0.37 & 0.71 \\
\hline Necrosis ${ }^{\mathrm{h}}$ & 0.64 & 0.30 & 0.28 & 0.77 \\
\hline
\end{tabular}

${ }^{\mathrm{a}}$ Low vs high.

${ }^{\mathrm{b}}$ Low vs high.

${ }^{\mathrm{c}}$ Under and overexpression vs underexpression/limited expression.

${ }^{\mathrm{d}}$ Absence vs presence of epithelioid component.

e $<15 \mathrm{~mm}$ vs $>15 \mathrm{~mm}$.

${ }^{\mathrm{f}}<8 \mathrm{~mm}$ vs $>8 \mathrm{~mm}$.

${ }^{\mathrm{L}}$ Low pigmentation vs high.

${ }^{\mathrm{h}}$ Limited necrosis vs extensive necrosis.

perinuclear expression after being irradiated with UV light. ${ }^{37}$ Yet, the role of autophagy and its links with hypoxia and the autophagy/hypoxia interaction in human melanomas remains obscure.

In this study, the autophagy-related proteins Atg8 $(M A P 1 L C 3 A)$ and Atg6 gene (BECN1) were used as immunohistochemical targets to detect autophagic activity in a series of 99 uveal melanomas.

Miracco et $a l^{38}$ investigating the expression of autophagic genes in cutaneous melanocytic lesions found a gradual decrease in these proteins with tumor progression; the proportion of cases with high cytoplasmic expression of LC3 declined from benign through dysplastic to malignant melanocytic lesions, being at lowest in metastatic melanomas. While a similar decrease in MAP1LC3A expression was reported in cerebral and ovarian cancer, ${ }^{39,40}$ in other malignancies, such as esophageal and gastrointestinal carcinomas, an increased LC3 expression was prevailing. ${ }^{41}$ There were also reports connecting an increased LC3 activity with poor outcome in pancreatic tumors and with a better survival in glioblastoma patients with poor performance score. ${ }^{40,42}$

In most of these studies, however, the expression of LC3 protein was reported as being consistently cytoplasmic, a staining pattern that was also seen with a frequency of $40 \%$ in our series of uveal melanomas, and which, presumably, corresponds to the soluble non-membrane-bound form of MAP1LC3A (MAP1LC3A-I). It should be mentioned, however, that a substantial proportion of cases amounting to $31 \%$ in our material, also showed a distinct perinuclear MAP1LC3A expression. This is not entirely unexpected, since an analogous 'paranuclear pinpoint stain' was described by Miracco et $a l^{38}$ in their series of cutaneous malignant melanomas. Rieber and Rieber ${ }^{37}$ investigating human C8161 melanoma cells, also noted that 30\% of UV-irradiated melanomas showed this juxta- or perinuclear pattern of expression. This is interesting as lysosomes usually accumulate to the perinuclear region where they fuse with cytoplasmic autophagosomes (a process also known as autophagocytosis) to form the autolysosomes. It appears, therefore, that the perinuclear MAP1LC3A expression may reflect an active autophagic function, as indicated by the accumulation of MAP1LC3A-II-positive autophagosomes to the perinuclear region of the lysosomal domain. ${ }^{43,44}$

The question, of course, remains why melanomas, whether uveal or cutaneous, are lacking 'stone-like' structures, despite being aggressive tumors. Obviously, there is no easy answer to that, but it is presumed that malignant melanocytic tumors, being endowed with a rich vascular supply, either need not require an accelerated form of autophagy to survive the adverse conditions of the microenvironment or that these tumors are more resistant to 
a

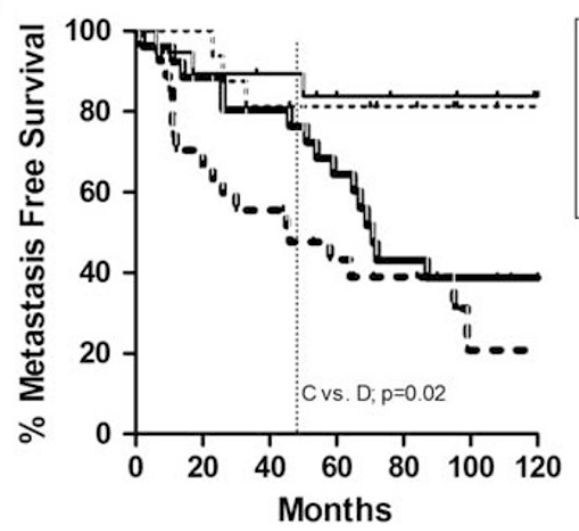

- A. Overexpression limited (19 pts)

.... B. Low-level (16 pts)

C. Underexpression (26 pts)

-D D. Overexpression extensive (27 pts)

b
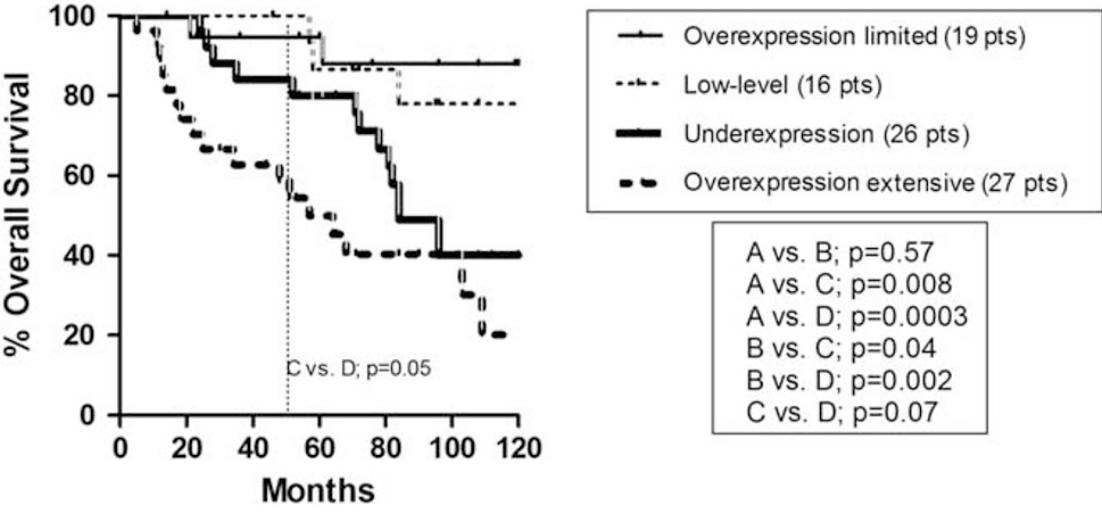

A vs. $B ; p=0.84$

A vs. $C ; p=0.01$

A vs. $D ; p=0.0007$

B vs. $C ; p=0.02$

$B$ vs. $D ; p=0.002$

C vs. D; $p=0.15$

Figure 3 Kaplan-Meier survival curves of (a) metastasis-free survival, and (b) overall disease-specific survival, stratified by BECN1 expression.

nutrient deprivation-a phenomenon known as austerity. ${ }^{45}$ Alternatively, there may be another, yet unsuspected, mechanism operative in malignant melanomas.

With regard to BECN1, an autophagy-related gene with tumor suppressor activity, Miracco et $a l^{38}$ reported comparable results to those shown for $M A P 1 L C 3 A$, that is gradual decline of cytoplasmic expression of BECN1 in cutaneous melanocytic lesions from $100 \%$ in benign nevi to $86.4 \%$ in dysplastic nevi, $54.3 \%$ in melanomas, and $26.7 \%$ in melanoma metastases. Such decreased cytoplasmic expression of $B E C N 1$ has been correlated with tumor progression in breast, ovarian, and cerebral neoplasms $^{39,46,47}$ and with a reduced survival rate in neoplasms of esophageal, colorectal, hepatocellular, and cerebral origin. ${ }^{4-51}$ Liang et $a l^{46}$ explained this immunohistochemical decline in cytoplasmic expression of the protein in terms of BECN1 inactivation and loss of its tumor suppressor functions. There have been, however, other tumors, including colorectal and gastric adenocarcinomas, in which progression appeared to be dependent upon an increased BECN1 expression. ${ }^{52}$

The above conflicting results, although may suggest different roles of BECN1 expression depending on cancer cell types, ${ }^{47,52}$ they may also imply the existence of various patterns of BECN1 expression up to date unrecognized. In this context, we hypothesized that there are four patterns of BECN1 expression, the low level of BECN1 expression, which may reflect a basal level of autophagic function; the overexpression of BECN1 (two grades), which apparently represent an intensification of the autophagic machinery under the adverse intratumoral conditions of hypoxia and acidity, as indicated in this and in other studies; $;^{50,53}$ and, of course, there may be a reduction or loss of BECN1 expression, a probable result of allelic gene deletions ${ }^{8}$ or a consequence of deregulated microRNA function, such as miT-30a. ${ }^{54}$ As BECN1 interacts with members of the bcl-2 protein acting as a tumor suppressor, ${ }^{55}$ potentiation of the anti-apoptotic machinery may account, at least in part, for the poor outcome of patients with reduced Beclin 1 expression.

Indeed, in the present study, both the underexpression and the excessive overexpression of $B E C N 1$ were linked with metastases and an overall poor disease-specific survival. However, the temporal patterns of metastases and death were distinct, as overexpression was correlated with a rapid onset of metastases, while the underexpression of $B E C N 1$ was linked with delayed onset of metastatic disease and delayed death rates after 4-5 years from surgery. As only overexpression was linked with hypoxia/acidity features (HIF1A and LDHA, LDH5 
isoenzyme), it is postulated that the reasons of disease progression largely differ between the two groups. MAP1LC3A expression, on the other hand, did not show any association of clinical importance, given that the association between high cytoplasmic or perinuclear expression and intense pigmentation does not seem to affect the outcome.

It is concluded that autophagy is upregulated in over $40-50 \%$ of uveal melanomas, and these cases were correlated with tumor hypoxia; the latter was inferred by the intimate relationship of MAP1LC3A and BECN1 with HIF1A and LDHA (LDH5 isoenzyme), the major LDH isoenzyme involved in anaerobic metabolism. The overexpression of BECN1, being linked with tumor hypoxia and acidity, was associated with poor prognosis. A low BECN1 expression, probably representing gene silencing mechanism in a subset of tumor, was also linked with death events but these were of delayed metastasis. Uveal melanomas with the presence of an epithelioid component showed a clear tendency for metastases and a reduced overall survival, but this has been known for long ${ }^{56}$ and needs no further comment. It will be of interest to investigate in the future the relation of autophagy with tumorinfiltrating macrophages in uveal melanomas.

\section{Acknowledgements}

We are grateful to Professor KC Gatter, University of Oxford, Oxford, UK, for providing us with the monoclonal antibody ESEE122/HIF1A. We also thank Mrs Karin Oberländer and Mrs Kyriaki Devetzi for their excellent technical assistance.

\section{Disclosure/conflict of interest}

The authors declare no conflict of interest.

\section{References}

1 Shintani T, Klionsky DJ. Autophagy in health and disease: a double-edged sword. Science 2004;306: 990-995.

2 Zois CE, Koukourakis MI. Radiation-induced autophagy in normal and cancer cells: towards novel cytoprotection and radio-sensitization policies? Autophagy 2009;5:442-450.

3 Mizushima N, Ohsumi Y, Yoshimori T. Autophagosome formation in mammalian cells. Cell Struct Funct 2002;27:421-429.

4 Kabeya Y, Mizushima N, Ueno T, et al. LC3, a mammalian homologue of yeast Apg8p, is localized in autophagosome membranes after processing. EMBO J 2000;19:5720-5728.

$5 \mathrm{Wu}$ J, Dang Y, Su W, et al. Molecular cloning and characterization of rat LC3A and LC3B-two novel markers of autophagosome. Biochem Biophys Res Commun 2006;339:437-442.
6 Liang XH, Yu J, Brown K, et al. Beclin 1 contains a leucine-rich nuclear export signal that is required for its autophagy and tumor suppressor function. Cancer Res 2001;61:3443-3449.

7 Karantza-Wadsworth V, White E. Role of autophagy in breast cancer. Autophagy 2007;3:610-613.

8 Aita VM, Liang XH, Murty VV, et al. Cloning and genomic organization of beclin 1 , a candidate tumor suppressor gene on chromosome 17q21. Genomics 1999;59:59-65.

$9 \mathrm{Qu} \mathrm{X}, \mathrm{Yu}$ J, Bhagat G, et al. Promotion of tumorigenesis by heterozygous disruption of the beclin 1 autophagy gene. J Clin Invest 2003;112:1809-1820.

10 Yue Z, Jin S, Yang C, et al. Beclin 1, an autophagy gene essential for early embryonic development, is a haploinsufficient tumor suppressor. Proc Natl Acad Sci USA 2003;100:15077-15082.

11 Edinger AL, Thompson CB. Defective autophagy leads to cancer. Cancer Cell 2003;4:422-424.

12 Giatromanolaki A, Sivridis E, Koukourakis MI. Tumour angiogenesis: vascular growth and survival. APMIS 2004;112:431-440.

13 Sivridis E, Giatromanolaki A, Koukourakis MI. The vascular network of tumours-what is it not for? J Pathol 2003;201:173-180.

14 Rouschop KM, Wouters BG. Regulation of autophagy through multiple independent hypoxic signaling pathways. Curr Mol Med 2009;9:417-424.

15 Semenza GL, Jiang BH, Leung SW, et al. Hypoxia response elements in the aldolase $\mathrm{A}$, enolase 1 , and lactate dehydrogenase A gene promoters contain essential binding sites for hypoxia-inducible factor 1 . J Biol Chem 1996;271:32529-32537.

16 Bellot G, Garcia-Medina R, Gounon P, et al. Hypoxiainduced autophagy is mediated through hypoxiainducible factor induction of BNIP3 and BNIP3 L via their BH3 domains. Mol Cell Biol 2009;29:2570-2581.

17 Zhang $\mathrm{H}$, Bosch-Marce $\mathrm{M}$, Shimoda LA, et al. Mitochondrial autophagy is an HIF-1-dependent adaptive metabolicresponse to hypoxia. J Biol Chem 2008;283:10892-10903.

18 Levine B, Yuan J. Autophagy in cell death: an innocent convict? J Clin Invest 2005;115:2679-2688.

19 Sivridis E, Koukourakis MI, Zois C, et al. LC3Apositive light microscopy detected patterns of autophagy and prognosis in operable breast carcinomas. Am J Pathol 2010;176:2477-2489.

20 Giatromanolaki A, Koukourakis MI, Harris AL, et al. Prognostic relevance of light chain 3 (LC3A) autophagy patterns in colorectal adenocarcinomas. J Clin Pathol 2010;63:867-872.

21 Sivridis E, Giatromanolaki A, Karpathiou G, et al. LC3A-positive 'stone-like' structures in cutaneous squamous cell carcinomas. Am J Dermatopathol; 11 March 2011; e-pub ahead of print.

22 Koukourakis MI, Giatromanolaki A, Sivridis E, et al. Beclin 1 over- and under-expression in colorectal cancer distinct patterns relate to prognosis and tumour hypoxia. Br J Cancer 2010;103:1209-1214.

23 Talks KL, Turley H, Gatter KC, et al. The expression and distribution of the hypoxia-inducible factors HIF-1alpha and HIF-2alpha in normal human tissues, cancers, and tumor-associated macrophages. Am J Pathol 2000;157:411-421.

24 Zaman K, Ryu H, Hall D, et al. Protection from oxidative stress-induced apoptosis in cortical neuronal cultures by iron chelators is associated with enhanced 
DNA binding of hypoxia-induciblefactor-1 and ATF-1/ CREB and increased expression of glycolytic enzymes, p21(waf1/cip1), and erythropoietin. J Neurosci 1999; 19:9821-9830.

25 Koukourakis MI, Giatromanolaki A, Simopoulos C, et al. Lactate dehydrogenase 5 (LDH5) relates to up-regulated hypoxia inducible factor pathway and metastasis in colorectal cancer. Clin Exp Metastasis 2005;22:25-30.

26 Koukourakis MI, Bentzen SM, Giatromanolaki A, et al. Endogenous markers of two separate hypoxia response pathways (hypoxia inducible factor 2 alpha and carbonic anhydrase 9) are associated with radiotherapy failure in head and neck cancer patients recruited in the CHART randomized trial. J Clin Oncol 2006;24:727-735.

27 Sivridis E, Giatromanolaki A, Zois C, et al. The 'stonelike' pattern of autophagy in human epithelial tumors and tumor-like lesions: an approach to the clinical outcome. Autophagy 2010;6:830-833.

28 Subarsky P, Hill RP. The hypoxic tumour microenvironment and metastatic progression. Clin Exp Metastasis 2003;20:237-250.

29 Brown JM, Wilson WR. Exploiting tumour hypoxia in cancer treatment. Nat Rev Cancer 2004; 4:437-447.

30 Gulliksrud K, Vestvik IK, Galappathi K, et al. Detection of different hypoxic cell subpopulations in human melanoma xenografts by pimonidazole immunohistochemistry. Radiat Res 2008;170:638-650.

31 Rofstad EK, Rasmussen H, Galappathi K, et al. Hypoxia promotes lymph node metastasis in human melanoma xenografts by up-regulating the urokinase-type plasminogen activator receptor. Cancer Res 2002;62: 1847-1853.

32 Rofstad EK, Mathiesen B, Henriksen K, et al. The tumor bed effect: increased metastatic dissemination from hypoxia-induced up-regulation of metastasispromoting gene products. Cancer Res 2005;65: 2387-2396.

33 Giatromanolaki A, Sivridis E, Kouskoukis C, et al. Hypoxia-inducible factors 1alpha and 2alpha are related to vascular endothelial growth factor expression and a poorer prognosis in nodular malignant melanomas of the skin. Melanoma Res 2003;13: 493-501.

34 Chang SH, Worley LA, Onken MD, et al. Prognostic biomarkers in uveal melanoma: evidence for a stem cell-like phenotype associated with metastasis. Melanoma Res 2008;18:191-200.

35 Bedogni B, Welford SM, Cassarino DS, et al. The hypoxic microenvironment of the skin contributes to Akt-mediated melanocyte transformation. Cancer Cell 2005;8:443-454.

36 Horikoshi T, Jimbow K, Sugiyama S. Comparison of macromelanosomes and autophagic giant melanosome complexes in nevocellular nevi, lentigo simplex and malignant melanoma. J Cutan Pathol 1982;9: 329-339.

37 Rieber M, Rieber MS. Sensitization to radiationinduced DNA damage accelerates loss of bcl-2 and increases apoptosis and autophagy. Cancer Biol Ther 2008;7:1561-1566.
38 Miracco C, Cevenini G, Franchi A, et al. Beclin 1 and LC3 autophagic gene expression in cutaneous melanocytic lesions. Hum Pathol 2010;41:503-512.

39 Shen Y, Li DD, Wang LL, et al. Decreased expression of autophagy-related proteins in malignant epithelial ovarian cancer. Autophagy 2008;16:1067-1068.

40 Aoki $\mathrm{H}$, Kondo $\mathrm{Y}$, Aldape $\mathrm{K}$, et al. Monitoring autophagy in glioblastoma with antibody against isoform B of human microtubule-associated protein 1 light chain 3. Autophagy 2008;4:467-475.

41 Yoshioka A, Miyata $\mathrm{H}$, Doki $\mathrm{Y}$, et al. LC3, an autophagosome marker, is highly expressed in gastrointestinal cancers. Int J Oncol 2008;33:461-468.

42 Fujii S, Mitsunaga S, Yamazaki M, et al. Autophagy is activated in pancreatic cancer cells and correlates with poor patient outcome. Cancer Sci 2008;99:1813-1819.

43 Kimura S, Noda T, Yoshimori T. Dynein-dependent movement of autophagosomes mediates efficient encounters with lysosomes. Cell Struct Funct 2008; 33:109-122.

44 Noda T, Fujita N, Yoshimori T. The late stages of autophagy: how does the end begin? Cell Death Differ 2009;16:984-990.

45 Sato K, Tsuchihara K, Fujii S, et al. Autophagy is activated in colorectal cancer cells and contributes to the tolerance to nutrient deprivation. Cancer Res 2007;67:9677-9684.

46 Liang XH, Jackson S, Seaman M, et al. Induction of autophagy and inhibition of tumorigenesis by beclin 1 . Nature 1999;402:672-676.

47 Miracco C, Cosci E, Oliveri G, et al. Protein and mRNA expression of autophagy gene Beclin 1 in human brain tumours. Int J Oncol 2007;30:429-436.

48 Chen Y, Lu Y, Lu C, et al. Beclin 1 expression is a predictor of clinical outcome in patients with esophageal squamous cell carcinoma and correlated to hypoxia-inducible factor (HIF)-1alpha expression. Pathol Oncol Res 2009;15:487-493.

49 Pirtoli L, Cevenini G, Tini P, et al. The prognostic role of beclin 1 protein expression in high-grade gliomas. Autophagy 2009;5:930-936.

50 Li BX, Li CY, Peng RQ, et al. The expression of beclin 1 is associated with favorable prognosis in stage IIIB colon cancers. Autophagy 2009;5:303-306.

51 Shi YH, Ding ZB, Zhou J, et al. Prognostic significance of Beclin 1-dependent apoptotic activity in hepatocellular carcinoma. Autophagy 2009;5:380-382.

52 Ahn CH, Jeong EG, Lee JW, et al. Expression of beclin1 , an autophagy-related protein, in gastric and colorectal cancers. APMIS 2007;115:1344-1349.

53 Samokhvalov V, Scott BA, Crowder CM. Autophagy protects against hypoxic injury in C. elegans. Autophagy 2008;4:1034-1041.

54 Zhu H, Wu H, Liu X, et al. Regulation of autophagy by a beclin 1-targeted microRNA, miR-30a, in cancer cells. Autophagy 2009;5:816-823.

55 Cao Y, Klionsky DJ. Physiological functions of Atg6/Beclin 1: a unique autophagy-related protein. Cell Res 2007;17:839-849.

56 Seddon JM, Albert DM, Lavin PT, et al. A prognostic factor study of disease-free interval and survival following enucleation for uveal melanoma. Arch Ophthalmol 1983;101:1894-1899. 